\title{
Adjusting output impedance using a PI controller to improve the stability of a single-phase inverter under weak grid
}

\author{
Jiao Jiao and R. M. Nelms
}

\begin{abstract}
Explored in this paper is the grid impedance effect on the stability of a single-phase grid connected inverter with an $L C$ filter based on an analysis of the inverter output impedance. For a single-phase grid connected inverter, a PI controller is often used to regulate the current injected into the grid. However, the control performance can be influenced when the inverter is connected to a weak grid. Also, the utility grid has background harmonic noise, which can make the injected current distorted. Therefore, analysis of the output impedance of a single-phase grid connected inverter is important for the robustness and stability of the system. By modeling the output impedance of inverter, it can be determined that the proportional gain and integral gain of the controller have an effect on the output impedance. Analytical results show that by adjusting the PI controller parameters, the ability for harmonic reduction and stability of the system can be improved. Simulation and experiments using a $1 \mathrm{~kW}$ single-phase grid connected inverter verify the effectiveness of the theoretical analysis.
\end{abstract}

Index Terms - Grid impedance, inverter output impedance, LC filter, PI controller, single-phase inverter

\section{INTRODUCTION}

$\mathrm{D}$ ISTRIBUTED generation technologies such as solar panels and wind turbines are being investigated because they are environmentally friendly. The voltage source inverter, which is the connection interface between distributed generation and the utility grid, plays an important role and has received more and more attention. An $L C$ filter or an $L C L$ filter is commonly used to reduce the pulse width modulation (PWM) switching harmonics. Generally, the $L C L$ filter has better performance in attenuating higher order harmonics and smaller component size and weight compared to an $L C$ filter. However, the $L C L$ filter is third order, which can introduce a resonant peak into the system that will cause an oscillation. For a small power inverter (a few $\mathrm{kW}$ ), an $L C$ filter is a better choice for the harmonic attenuation. In this paper, we employ an $L C$ filter for the single-phase grid connected inverter.

In the case of long distribution lines and lower power

Submitted on: 27 Sep. 2016 . Accepted on: 30 Oct. 2016

Jiao Jiao is with the Electrical and Computer Engineering Department, Auburn University, Auburn, AL 36849 USA. (e-mail: jzj0034@auburn.edu).

R. M. Nelms is with the Electrical and Computer Engineering Department, Auburn University, Auburn, AL 36849 USA. (e-mail: nelmsrm@auburn.edu). transformers in a distribution system, the grid can have a large impedance, which is a typical weak grid. However, the controller design for a grid-connected inverter usually doesn't take the grid impedance into consideration. When a voltage source inverter is connected into a weak grid, the inverter control performance can be influenced [1]. The variation of the grid impedance may decrease the current controller bandwidth. In order to find the effect of grid impedance on the stability of the system, the external characteristics of the inverter need to be explored. Generally, it can be modeled by the output impedance of the inverter. The relationship between the output impedance of the inverter and the grid impedance has been studied by many researchers [2-4]. For stability analysis, the impedance-based stability criterion can be used to examine the ratio of the inverter output impedance to the grid impedance [2]. However, it doesn't mention a way to improve the stability of the system. In order to reduce the effect of grid impedance, the output impedance can be regulated accordingly. The output impedance depends on the design of the $L C$ filter and the control structure and parameters. To improve the stability of the system and the ability for harmonic rejection, the output impedance can be changed by adjusting the controller parameters. Therefore, the output impedance based method is explored under a weak and distorted grid.

In this paper, a $1 \mathrm{~kW}$ single-phase grid connected inverter is used to investigate the output impedance of the system. By analyzing the output impedance in the frequency domain, the controller parameters can be adjusted to regulate the output impedance. By increasing the proportional gain of the PI controller, the magnitude of the output impedance can be increased to improve the ability for harmonic rejection. By increasing the integral gain of the PI controller, the phase of the output impedance can be increased to improve the stability of system. Experimental results are in agreement with simulation analysis.

\section{Stability ANALysis of A Single-Phase INVERTER CONSIDERING GRID IMPEDANCE VARIATION}

\section{A. Modeling of the single-phase inverter}

The structure of a single-phase grid connected inverter with an $L C$ filter is presented in Fig. 1. $V_{d c}$ is the input DC link voltage, $v_{i n v}$ is the output voltage of the H-bridge inverter and 
$v_{g}$ is the utility grid voltage. The $L C$ filter consists of inverter side inductances $L_{1}$ and $L_{2}$ and a filter capacitance $C$. The inductances $L_{1}$ and $L_{2}$ are two equal inductances used for attenuating the common mode noise current in the circuit. In addition, the electromagnetic interference (EMI) effects are alleviated. $L_{g}$ is the grid impedance. The inductor current $i_{L}$, is used for current control to regulate the injected current with lower harmonics and unity power factor. The utility grid is sensed using a phase loop lock (PLL) to make the single-phase inverter synchronize with the grid voltage.

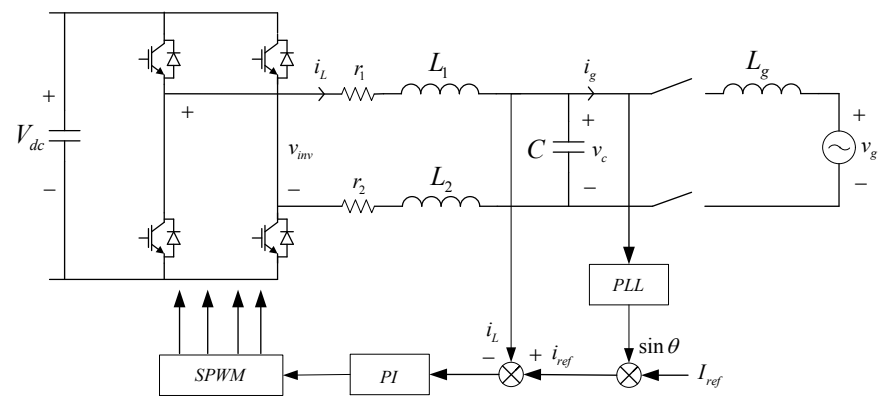

Fig. 1. Single-phase grid connected inverter with $L C$ filter

According to Kirchhoff's voltage law, we can get the circuit equation shown as follows:

$$
\left(L_{1}+L_{2}\right) \frac{d i_{L}}{d t}+\left(r_{1}+r_{2}\right) i_{L}=v_{i n v}-v_{c}
$$

Where $r_{1}$ and $r_{2}$ are the parasitic resistances of the inductors. By transforming to the frequency domain, the transfer function between inductor current and the difference between the inverter output voltage and the capacitor voltage can be derived.

$$
G_{p}(s)=\frac{I_{L}(s)}{V_{\text {inv }}(s)-V_{c}(s)}=\frac{1}{L s+R}
$$

\section{B. Output impedance of a single-phase inverter}

Many power converters are digitally controlled which will introduce sampling and computational delays into the system. Also, the PWM process will introduce delay due to a zeroorder hold [5]. Therefore, the total delay can be approximated by one and a half sampling period, which can be expressed by $G_{d}(s)$ shown below.

$$
G_{d}(s)=e^{-1.5 T s} \approx \frac{1}{1+1.5 T s}
$$

The variable $T$ is the sampling period. A PI controller is applied for current control in this inverter. The transfer function of a PI controller is shown as follows:

$$
G_{c}(s)=k_{p}\left(1+\frac{1}{\tau_{i} s}\right)
$$

Here $k_{p}$ is the proportional gain and $\tau_{i}$ is the integral gain. The system control block diagram is shown in Fig. 2 [6]. Fig. 2(a) can be simplified to Fig. 2(b) by control block equivalent transformations. The resulting transfer function of $G_{I}(s)$ and $G_{2}(s)$ can be expressed by:

$$
\begin{gathered}
G_{1}(s)=\frac{K_{p w m} G_{c}(s) G_{d}(s)}{L s+R+K_{p w m} G_{c}(s) G_{d}(s)} \\
G_{2}(s)=\frac{s L+R+K_{p w m} G_{c}(s) G_{d}(s)}{L C s^{2}+R C s+K_{p w m} G_{c}(s) G_{d}(s) C s+1}
\end{gathered}
$$

The output impedance of the inverter can be defined by:

$$
Z_{o}(s)=\left.\frac{v_{c}(s)}{-i_{g}(s)}\right|_{i_{r e f}=0}=G_{2}(s)
$$

Where $L=L_{1}+L_{2}, R=r_{1}+r_{2}$.

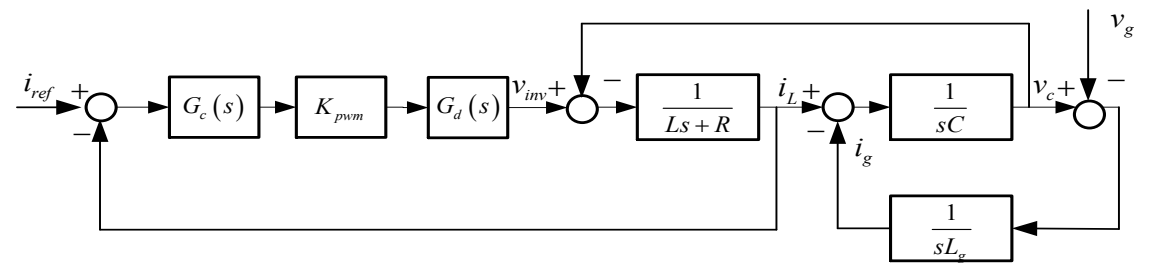

(a)
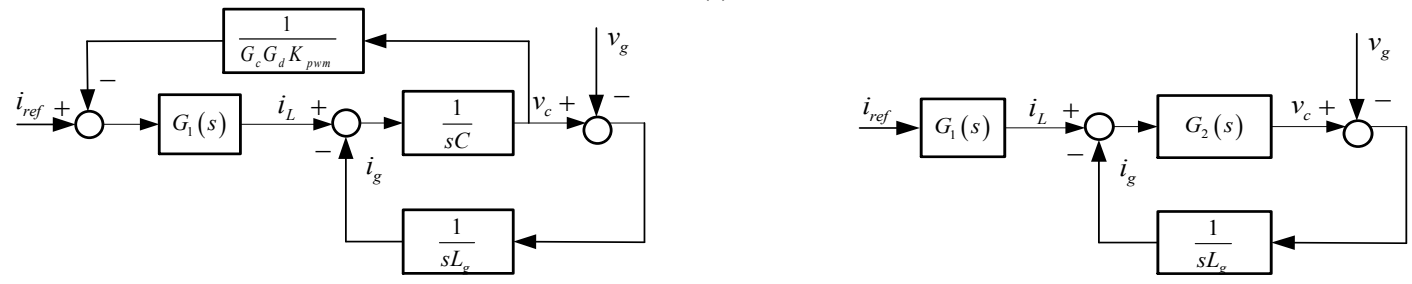

(b)

Fig. 2. Control block diagram for a single-phase grid connected inverter (a) and its equivalent transformation (b) 
Therefore, the single-phase grid connected inverter with an $L C$ filter can be modeled by the Norton equivalent circuit, as shown in Fig. 3. The inverter is represented by a current source and a parallel output impedance, and the utility grid is modeled by a voltage source and a grid impedance [2]. In this effort, only the grid inductance is considered in the analysis as a worst case scenario. In reality, the resistance in the grid will help to stabilize the system.

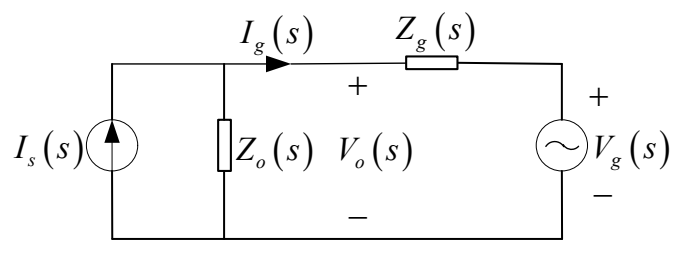

Fig. 3. Norton equivalent circuit

An expression for the inverter output current can be derived by:

$$
I_{g}(s)=\frac{1}{1+Z_{g} / Z_{o}} I_{s}(s)-\frac{1 / Z_{o}}{1+Z_{g} / Z_{o}} V_{g}(s)
$$

From (8), it can be found that in order to mitigate the effect caused by grid voltage and grid impedance variation, the output impedance should be designed as high as possible to operate stably [2]. It can be found from (7) that the output impedance depends on the design of the $L C$ filter and the controller structure and parameters. Therefore, the inverter output impedance can be shaped by adjusting the controller parameters to improve the system stability.

\section{Relationship between inverter output impedance and grid impedance}

A current controller is designed by assuming that the inverter is connected into an ideal grid $\left(L_{g}=0\right)$. The bode plot of the uncompensated system (without a current controller) and the bode plot of the compensated system (with current controller) are shown in Fig. 4. When the inverter is connected into a utility grid, the grid impedance can influence the inverter control performance. Fig. 5 shows the relationship between inverter output impedance and grid impedances in the frequency domain. According to [3-4], the stability of the inverter depends on the inverter output impedance's phase at the intersection point of $Z_{o}$ and $Z_{g}$. With an increase in the grid impedance, the phase of the output impedance at the intersection frequency point is decreasing, which implies the system is less stable.

In order to enhance the stability of the system under a wide range of grid impedance, the phase of the inverter output impedance at the intersection point should be increased by shaping the current controller parameters. The magnitude of inverter output impedance also needs to be designed higher to achieve better harmonic rejection ability.

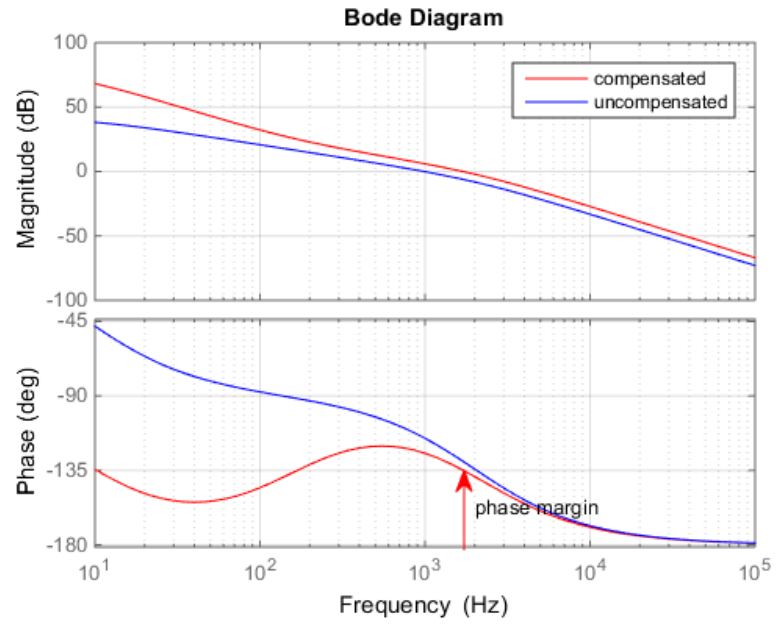

Fig. 4. Bode plot of the compensated and uncompensated system

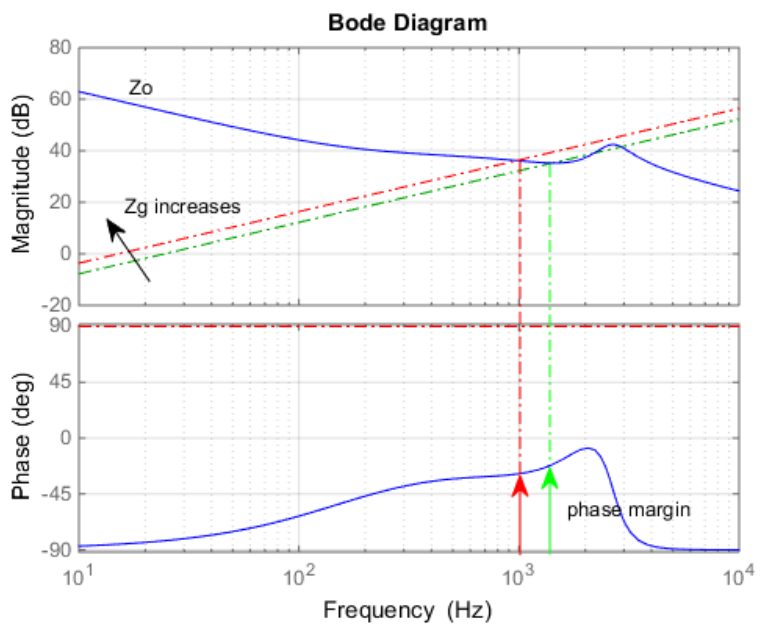

Fig. 5. Bode plot of the inverter output impedance and different grid impedances

\section{Shaping PI controller parameters to improve the stability of system under weak grid}

By analyzing (7), it can be determined that the output impedance of the inverter can be changed by adjusting the parameters of the PI controller. As seen in Fig. 6, the lower frequency part of the bode diagram shows that the magnitude of the output impedance increases with increasing proportional gain $k_{p}$, which improves the ability for harmonic reduction. However, the phase of the inverter output impedance is decreasing, which means the system might be becoming less stable.

As for increasing the integral gain of the PI controller, the phase of the inverter output impedance at the intersection frequency is increased, but the magnitude of the output impedance is decreased in the low frequency range. In the high frequency range, the magnitude and phase of inverter output impedance does not change much. It can be concluded that increasing the integral gain has the opposite effect on the output impedance as compared to increasing the proportional 
gain of the controller. Therefore, it is possible to increase the magnitude and phase of the output impedance by adjusting the PI controller parameters without affecting the performance of the inverter.
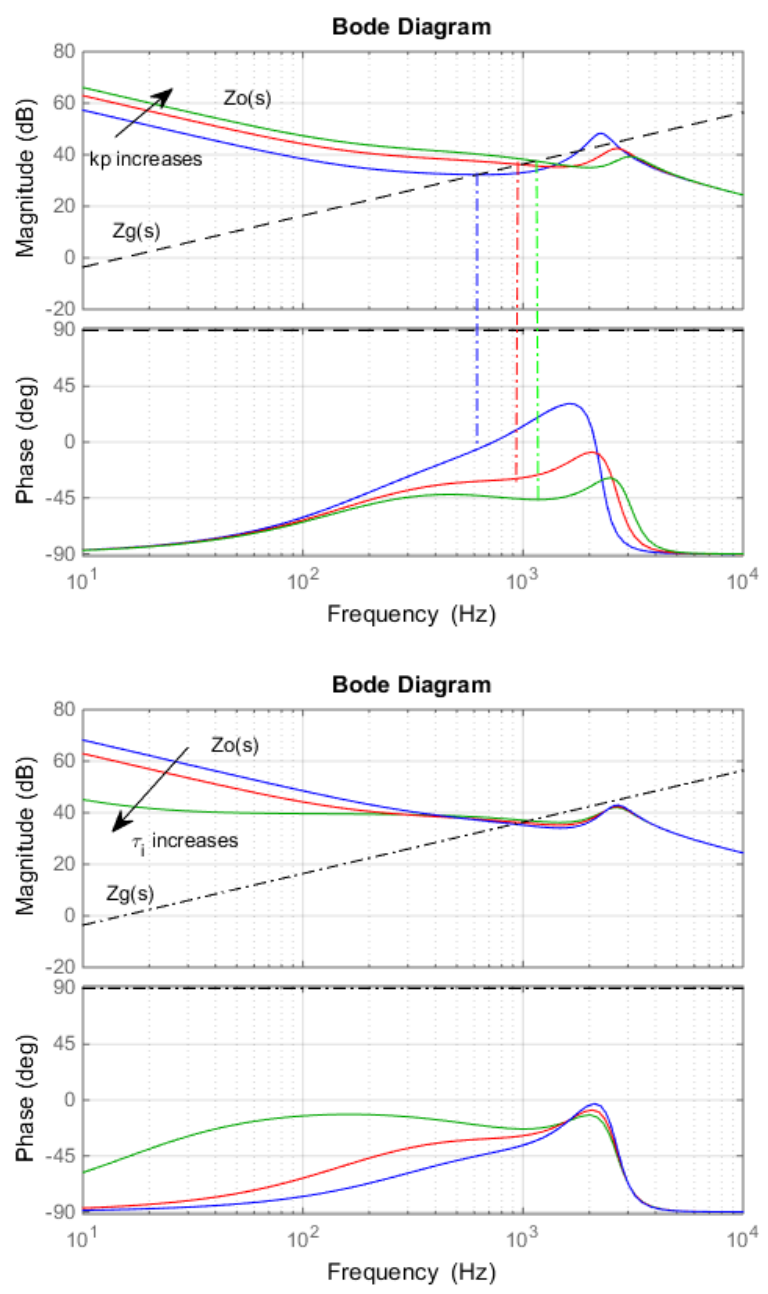

Fig. 6. Bode plot of inverter output impedance and grid impedance (a) proportional gain changes (top) (b) integral gain changes (bottom)

\section{E. Output impedance sensitivity to circuit parameters}

From (7), it can be found that the inverter output impedance depends on the circuit parameters and controller parameters. In reality, the circuit parameters can change due to the temperature variation of the surrounding environment. Therefore, it is necessary to explore the effect of circuit parameter variations on the inverter output impedance. Since the parasitic resistance of the filter inductors has little effect on the inverter output impedance, the resistance variation is not investigated here.

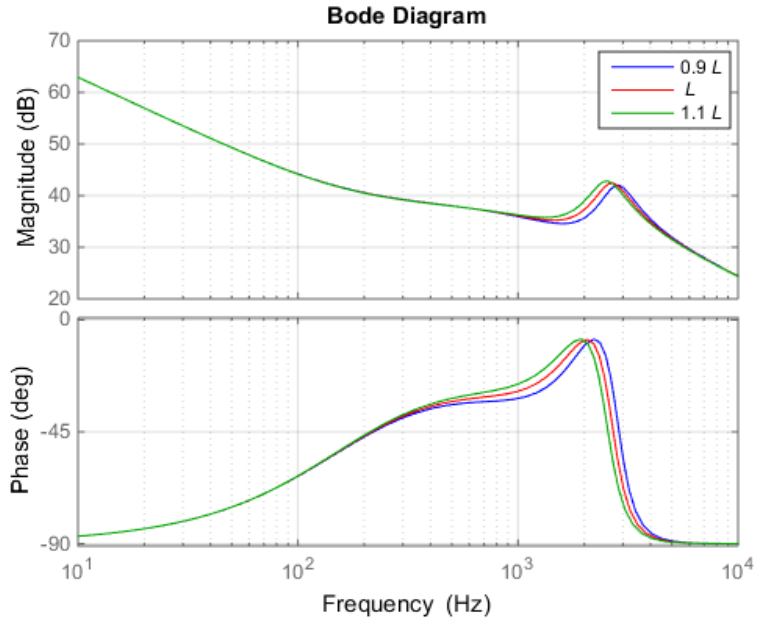

Fig. 7. The inverter output impedance sensitivity to inductance variation

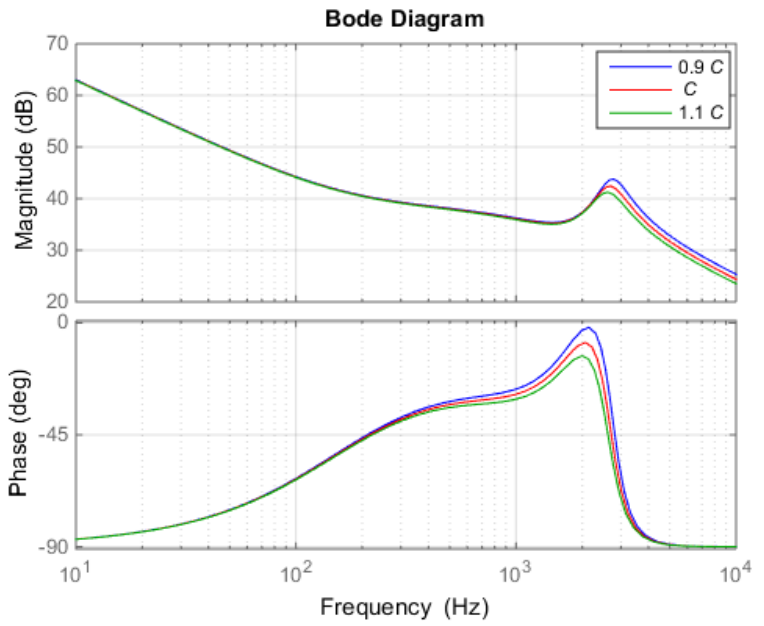

Fig. 8. The inverter output impedance sensitivity to capacitance variation

From Fig. 7, it can be seen that the frequency response of the inverter output impedance shifts to the left slightly as the inductance increases. It mainly affects the magnitude and phase of inverter output impedance around the peak. As shown in Fig. 8, with the increase of filter capacitance, the magnitude of the inverter output impedance remains unchanged in low frequency range, but it decreases in the high frequency range. The phase margin of the inverter output impedance is also decreased.

\section{SimUlation RESUlts}

The system shown in Fig. 1 is simulated by MATLAB to validate the theoretical analysis. The system parameters are given in Table I. For the simulation, the utility grid voltage $\left(\mathrm{v}_{\mathrm{g}}\right.$ in Fig. 1) is modeled by $7 \%$ third harmonics and $5 \%$ fifth harmonics and $3 \%$ seventh harmonics with phase $30^{\circ}, 90^{\circ}$ and $270^{\circ}$, respectively. 
TABLE I

CIRCUIT PARAMETERS

\begin{tabular}{ccc}
\hline \hline Circuit Parameter & Symbol & Value \\
\hline DC-link Voltage & $V_{d c}$ & $380 \mathrm{~V}$ \\
Utility Grid Voltage & $v_{g}$ & $120 \mathrm{~V}$ \\
Fundamental Frequency & $f_{0}$ & $60 \mathrm{~Hz}$ \\
Inverter Inductance & $L$ & $7 \mathrm{mH}$ \\
Inductance parasite resistance & $R$ & $0.4 \Omega$ \\
Filter Capacitance & $C$ & $1 \mu \mathrm{F}$ \\
Switching Frequency & $f_{s}$ & $19.2 \mathrm{kHz}$ \\
\hline \hline
\end{tabular}

Fig. 9 to Fig. 10 show the simulation results when the proportional gain was changed from $k_{p}=2$ to $k_{p}=3$; the grid impedance was $19.5 \mathrm{mH}$. The grid current total harmonic distortion (THD) is $4.30 \%$ and $3.76 \%$, respectively. The harmonic reduction ability is improved, which validates the analysis in Section II. Fig. 11 to Fig. 12 show the simulation results when the integral gain was changed from $\tau_{i}=0.0005$ to $\tau_{i}=0.01$; the grid impedance was $19.5 \mathrm{mH}$. The grid current total harmonic distortion (THD) is $4.51 \%$ and $4.83 \%$, respectively. Table II and Table III show the harmonic analysis of the inverter output current.

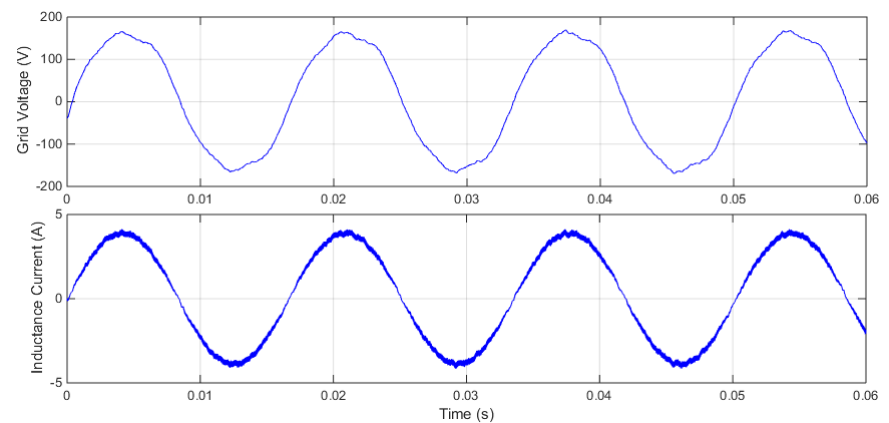

Fig. 9. Output voltage and output current when $L_{g}=19.5 \mathrm{mH}\left(k_{p}=2\right)$

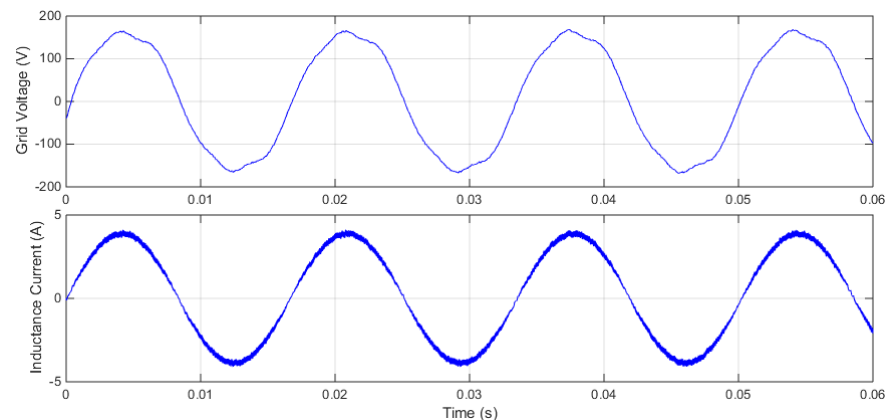

Fig. 10. Output voltage and output current when $L_{g}=19.5 \mathrm{mH}\left(k_{p}=3\right)$
TABLE II

OUTPUT CURRENT HARMONIC ANALYSIS

\begin{tabular}{c|c|c|c|c}
\hline \hline \multirow{2}{*}{$\begin{array}{c}\text { Harmonic } \\
\text { Order }\end{array}$} & \multicolumn{2}{|c|}{$L_{g}=6.5 \mathrm{mH}$} & \multicolumn{2}{c}{$L_{g}=19.5 \mathrm{mH}$} \\
\cline { 2 - 5 } & $k_{p}=2$ & $k_{p}=3$ & $k_{p}=2$ & $k_{p}=3$ \\
\hline 3rd & $0.71 \%$ & $0.73 \%$ & $1.12 \%$ & $0.88 \%$ \\
5th & $0.34 \%$ & $0.42 \%$ & $0.53 \%$ & $0.17 \%$ \\
7 th & $0.45 \%$ & $0.33 \%$ & $0.53 \%$ & $0.32 \%$ \\
9th & $0.16 \%$ & $0.17 \%$ & $0.24 \%$ & $0.25 \%$ \\
11th & $0.13 \%$ & $0.15 \%$ & $0.19 \%$ & $0.18 \%$ \\
13th & $0.16 \%$ & $0.10 \%$ & $0.12 \%$ & $0.18 \%$ \\
THD & $3.76 \%$ & $3.51 \%$ & $4.30 \%$ & $3.76 \%$ \\
\hline \hline
\end{tabular}
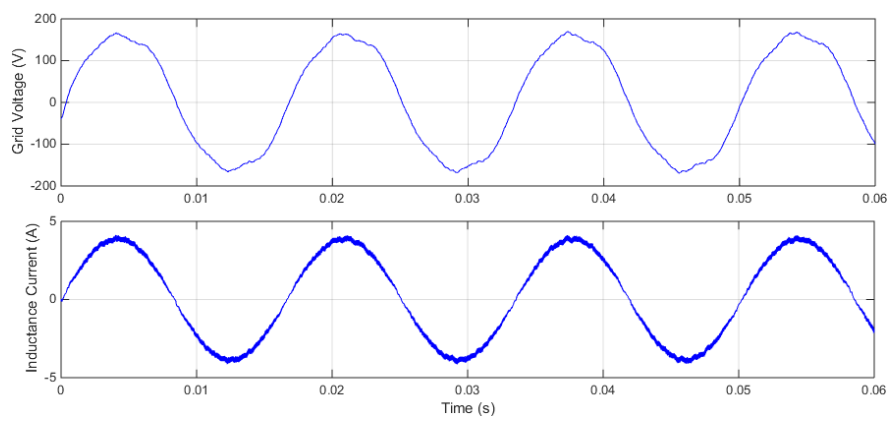

Fig. 11. Output voltage and output current when $L_{g}=19.5 \mathrm{mH}\left(\tau_{i}=0.0005\right)$

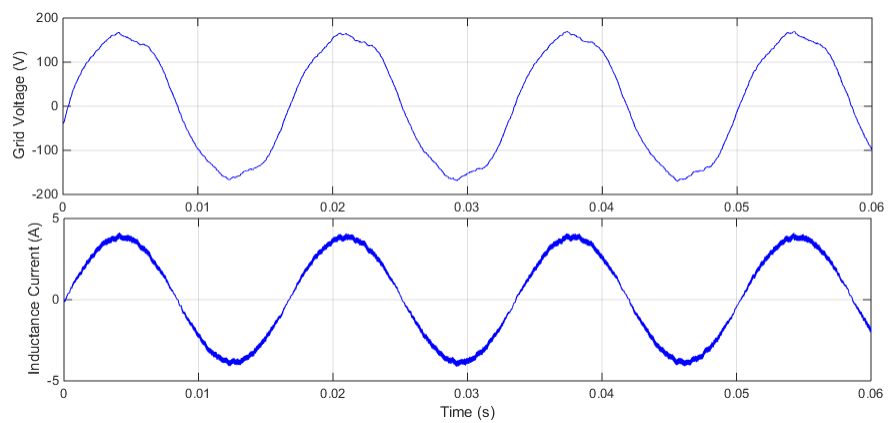

Fig. 12. Output voltage and output current when $L_{g}=19.5 \mathrm{mH}\left(\tau_{i}=0.01\right)$

TABLE III

\begin{tabular}{c|c|c|c|c}
\multicolumn{4}{c}{ TABLE III } \\
\hline \hline \multirow{2}{*}{$\begin{array}{c}\text { Harmonic } \\
\text { Order }\end{array}$} & \multicolumn{2}{|c|}{$L_{g}=6.5 \mathrm{mH}$} & \multicolumn{2}{c}{$L_{g}=19.5 \mathrm{mH}$} \\
\cline { 2 - 5 } & $\tau_{i}=0.0005$ & $\tau_{i}=0.01$ & $\tau_{i}=0.0005$ & $\tau_{i}=0.01$ \\
\hline 3rd & $0.52 \%$ & $0.74 \%$ & $0.74 \%$ & $0.98 \%$ \\
5 th & $0.34 \%$ & $0.29 \%$ & $0.14 \%$ & $0.49 \%$ \\
7 th & $0.37 \%$ & $0.46 \%$ & $0.28 \%$ & $0.45 \%$ \\
9 th & $0.14 \%$ & $0.25 \%$ & $0.28 \%$ & $0.40 \%$ \\
11th & $0.05 \%$ & $0.01 \%$ & $0.20 \%$ & $0.12 \%$ \\
13th & $0.15 \%$ & $0.10 \%$ & $0.11 \%$ & $0.04 \%$ \\
THD & $3.51 \%$ & $3.77 \%$ & $4.51 \%$ & $4.83 \%$ \\
\hline \hline
\end{tabular}

\section{EXPERIMENTAL RESULTS}

A $1 \mathrm{~kW}$ Texas Instruments single-phase grid connected inverter with an $L C$ filter was utilized for the experimental 
investigation. An ideal and a distorted grid voltage were simulated using a programmable $\mathrm{AC}$ source. In order to examine the effect of the grid impedance, an adjustable impedance is inserted between the inverter and the AC source. The measured single-phase inverter output voltage and output current are presented in Fig.13- Fig. 22. The inverter output current harmonics measured by Tektronix oscilloscope are given in Table IV and Table VII. Under the ideal grid, the THD of inverter output current was reduced from $4.94 \%$ to $4.65 \%$ by increasing the proportional gain of current controller when the grid impedance is $19.5 \mathrm{mH}$. The output voltage and output current without PI controller is also measured for comparison, which demonstrate the current distortion can be improved by shaping PI controller parameters. The THD of the inverter output current was decreased from $5.09 \%$ to $4.73 \%$ by decreasing the integral gain of the current controller when $L_{g}$ is $19.5 \mathrm{mH}$. Under the distorted grid, the THD of inverter output current was reduced from $5.21 \%$ to $4.69 \%$ by increasing the proportional gain of current controller when the grid impedance is $19.5 \mathrm{mH}$. The THD of the inverter output current was decreased from $5.28 \%$ to $4.74 \%$ by decreasing the integral gain of the current controller. As can be seen from these results, the THD of the inverter output current can be reduced by adjusting the PI controller gains. Because the single-phase inverter is connected to the $\mathrm{AC}$ source through a transformer and relay, which makes the grid side inductance larger than the grid impedance in the simulation, the THD of experimental results are higher than the THD of simulation results. But it's still in agreement with the theoretical analysis.

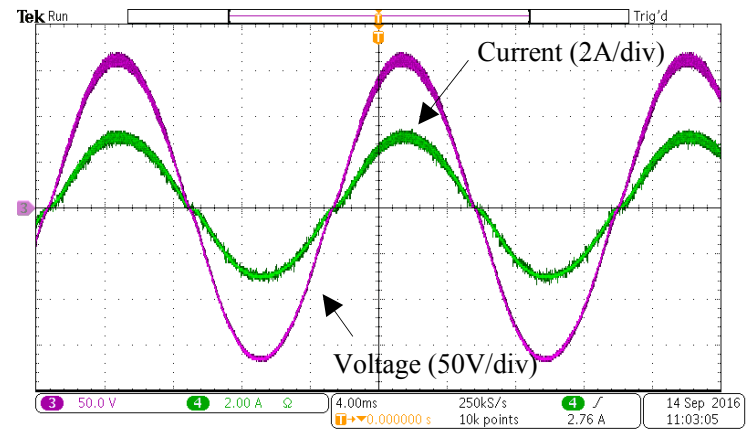

Fig. 13. Output voltage and output current when $L_{g}=19.5 \mathrm{mH}$ (without PI)

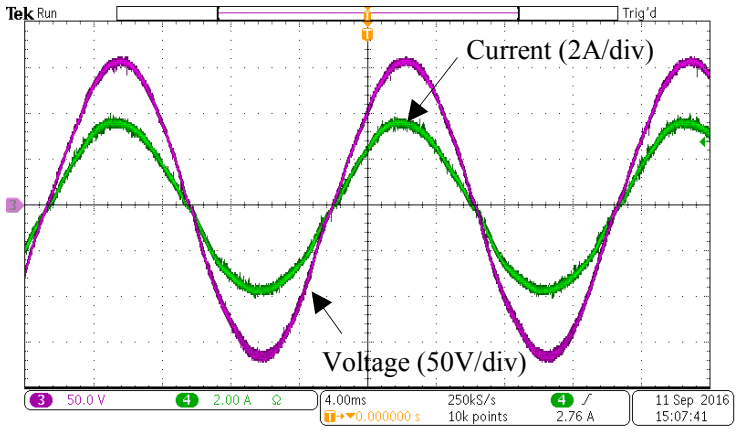

Fig. 14. Output voltage and output current when $L_{g}=19.5 \mathrm{mH}\left(k_{p}=2\right)$

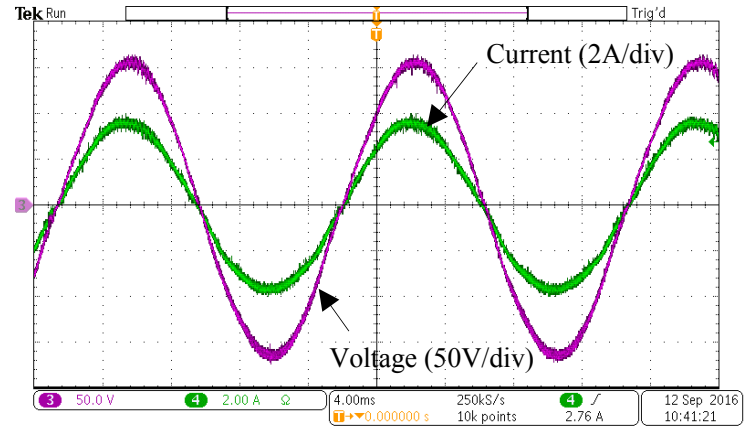

Fig. 15. Output voltage and output current when $L_{g}=19.5 \mathrm{mH}\left(k_{p}=3\right)$

TABLE IV

OUTPUT CURRENT HARMONIC ANALYSIS

\begin{tabular}{c|c|c|c|c|c|c}
\hline \hline \multirow{2}{*}{$\begin{array}{c}\text { Harmonic } \\
\text { Order }\end{array}$} & \multicolumn{3}{|c|}{$L_{g}=6.5 \mathrm{mH}$} & \multicolumn{3}{c}{$L_{g}=19.5 \mathrm{mH}$} \\
\cline { 2 - 7 } & No PI & $k_{p}=2$ & $k_{p}=3$ & No PI & $k_{p}=2$ & $k_{p}=3$ \\
\hline 3rd & $6.87 \%$ & $2.34 \%$ & $1.54 \%$ & $7.29 \%$ & $2.70 \%$ & $1.55 \%$ \\
5th & $5.53 \%$ & $1.52 \%$ & $0.91 \%$ & $5.71 \%$ & $1.63 \%$ & $0.72 \%$ \\
7th & $2.83 \%$ & $1.77 \%$ & $1.37 \%$ & $2.64 \%$ & $1.91 \%$ & $1.67 \%$ \\
9th & $1.70 \%$ & $1.97 \%$ & $1.61 \%$ & $1.61 \%$ & $2.20 \%$ & $1.61 \%$ \\
11th & $1.09 \%$ & $1.00 \%$ & $0.73 \%$ & $1.09 \%$ & $1.18 \%$ & $0.86 \%$ \\
13th & $1.03 \%$ & $0.69 \%$ & $0.77 \%$ & $0.89 \%$ & $0.91 \%$ & $0.68 \%$ \\
THD & $6.83 \%$ & $4.85 \%$ & $4.64 \%$ & $6.61 \%$ & $4.94 \%$ & $4.65 \%$ \\
\hline \hline
\end{tabular}

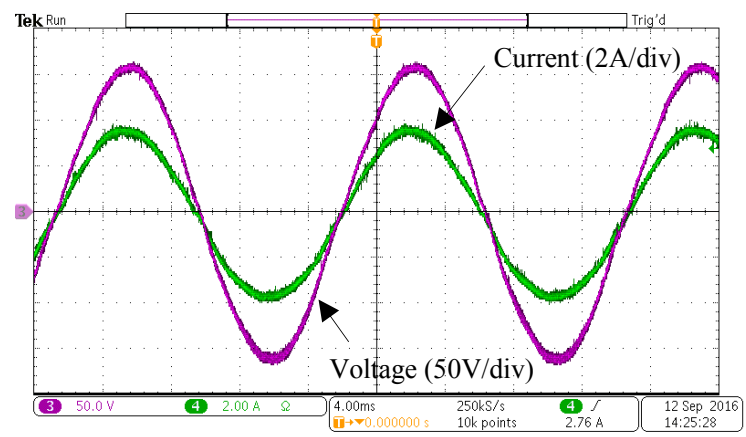

Fig. 16. Output voltage and output current when $L_{g}=19.5 \mathrm{mH}\left(\tau_{i}=0.0005\right)$

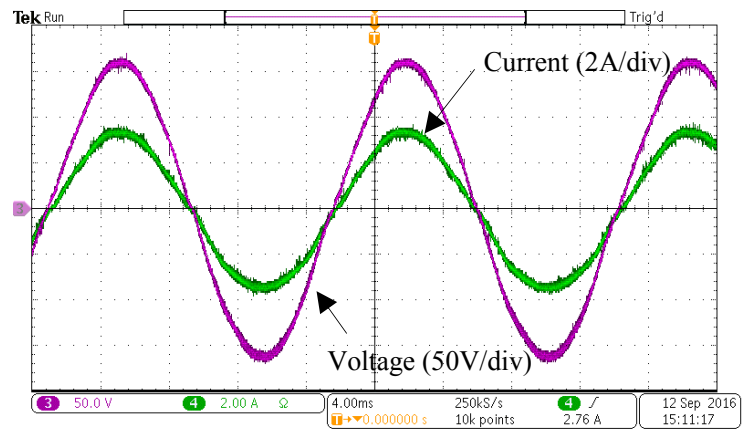

Fig. 17. Output voltage and output current when $L_{g}=19.5 \mathrm{mH}\left(\tau_{i}=0.01\right)$ 
TABLE V

OUTPUT CURRENT HARMONIC ANALYSIS

\begin{tabular}{c|c|c|c|c}
\hline \hline \multirow{2}{*}{$\begin{array}{c}\text { Harmonic } \\
\text { Order }\end{array}$} & \multicolumn{2}{|c|}{$L_{g}=6.5 \mathrm{mH}$} & \multicolumn{2}{c}{$L_{g}=19.5 \mathrm{mH}$} \\
\cline { 2 - 5 } & $\tau_{i}=0.0005$ & $\tau_{i}=0.01$ & $\tau_{i}=0.0005$ & $\tau_{i}=0.01$ \\
\hline 3rd & $1.82 \%$ & $2.29 \%$ & $2.33 \%$ & $2.05 \%$ \\
5 th & $0.98 \%$ & $1.80 \%$ & $0.92 \%$ & $2.01 \%$ \\
7th & $1.57 \%$ & $2.02 \%$ & $1.54 \%$ & $1.77 \%$ \\
9th & $2.13 \%$ & $1.96 \%$ & $1.58 \%$ & $1.93 \%$ \\
11 th & $1.31 \%$ & $0.72 \%$ & $0.77 \%$ & $0.63 \%$ \\
13 th & $0.94 \%$ & $0.54 \%$ & $0.54 \%$ & $0.40 \%$ \\
THD & $4.78 \%$ & $5.28 \%$ & $4.73 \%$ & $5.09 \%$ \\
\hline \hline
\end{tabular}

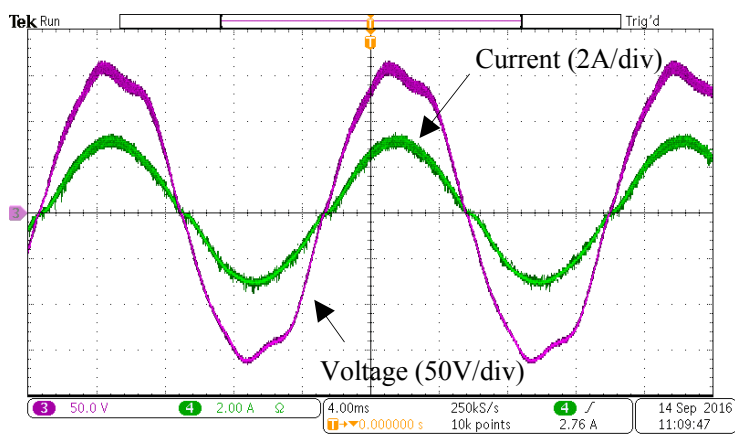

Fig. 18. Output voltage and output current when $L_{g}=19.5 \mathrm{mH}$ (without PI)

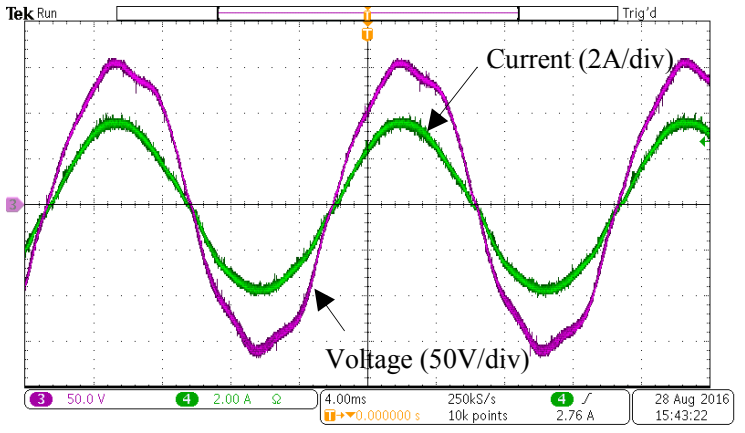

Fig. 19. Output voltage and output current when $L_{g}=19.5 \mathrm{mH}\left(k_{p}=2\right)$

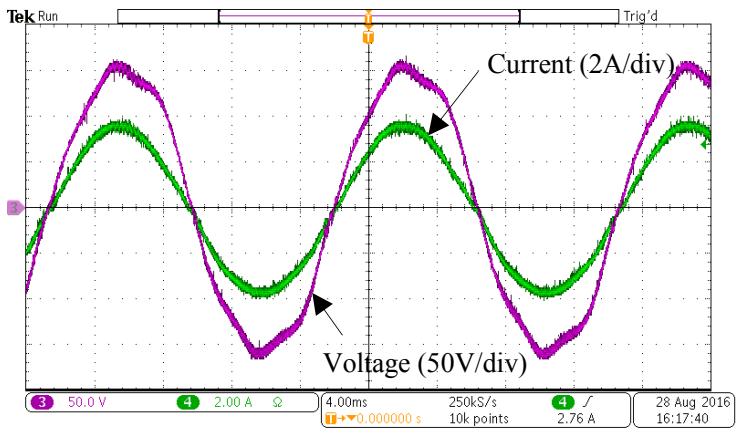

Fig. 20. Output voltage and output current when $L_{g}=19.5 \mathrm{mH}\left(k_{p}=3\right)$
TABLE VI

OUTPUT CURRENT HARMONIC ANALYSIS

\begin{tabular}{c|c|c|c|c|c|c}
\hline \hline \multirow{2}{*}{$\begin{array}{c}\text { Harmonic } \\
\text { Order }\end{array}$} & \multicolumn{3}{|c|}{$L_{g}=6.5 \mathrm{mH}$} & \multicolumn{3}{c}{$L_{g}=19.5 \mathrm{mH}$} \\
\cline { 2 - 7 } & No PI & $k_{p}=2$ & $k_{p}=3$ & No PI & $k_{p}=2$ & $k_{p}=3$ \\
\hline 3rd & $7.62 \%$ & $3.80 \%$ & $2.71 \%$ & $8.10 \%$ & $3.47 \%$ & $2.39 \%$ \\
5th & $3.56 \%$ & $1.68 \%$ & $1.52 \%$ & $4.43 \%$ & $1.92 \%$ & $0.76 \%$ \\
7th & $4.51 \%$ & $1.90 \%$ & $1.28 \%$ & $3.90 \%$ & $2.02 \%$ & $1.24 \%$ \\
9th & $1.64 \%$ & $1.57 \%$ & $1.14 \%$ & $1.61 \%$ & $1.95 \%$ & $1.45 \%$ \\
11 th & $1.13 \%$ & $0.85 \%$ & $0.55 \%$ & $1.09 \%$ & $1.22 \%$ & $0.94 \%$ \\
13 th & $1.05 \%$ & $0.92 \%$ & $0.52 \%$ & $1.08 \%$ & $0.74 \%$ & $0.74 \%$ \\
THD & $6.91 \%$ & $5.09 \%$ & $4.77 \%$ & $6.86 \%$ & $5.21 \%$ & $4.69 \%$ \\
\hline \hline
\end{tabular}

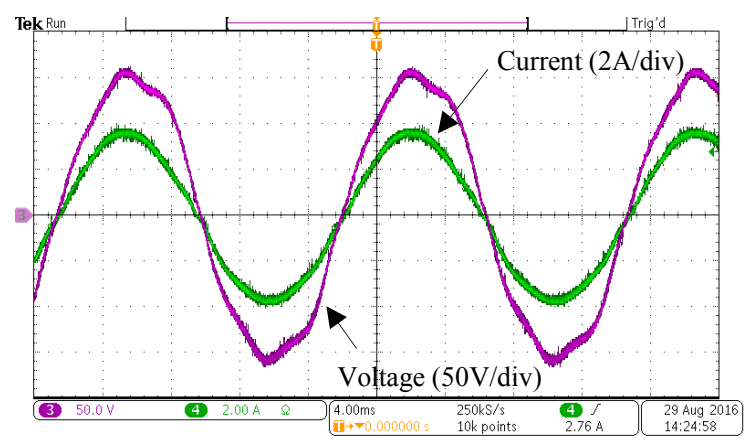

Fig. 21. Output voltage and output current when $L_{g}=19.5 \mathrm{mH}\left(\tau_{i}=0.0005\right)$

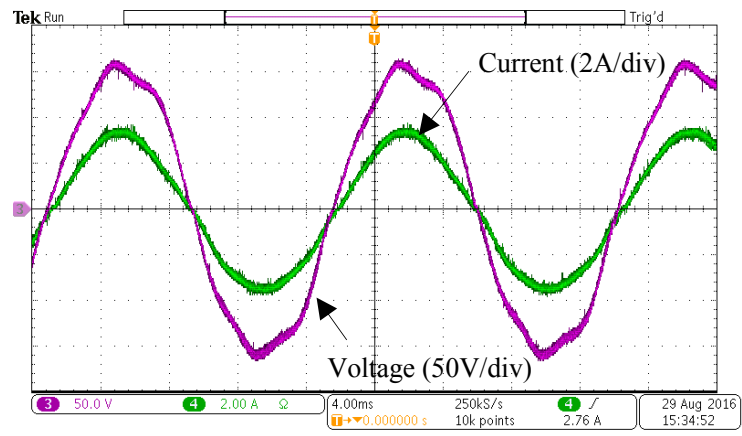

Fig. 22. Output voltage and output current when $L_{g}=19.5 \mathrm{mH}\left(\tau_{i}=0.01\right)$

TABLE VII

OUTPUT CURRENT HARMONIC ANALYSIS

\begin{tabular}{c|c|c|c|c}
\hline \hline \multirow{2}{*}{$\begin{array}{c}\text { Harmonic } \\
\text { Order }\end{array}$} & \multicolumn{2}{|c|}{$L_{g}=6.5 \mathrm{mH}$} & \multicolumn{2}{c}{$L_{g}=19.5 \mathrm{mH}$} \\
\cline { 2 - 5 } & $\tau_{i}=0.0005$ & $\tau_{i}=0.01$ & $\tau_{i}=0.0005$ & $\tau_{i}=0.01$ \\
\hline 3 rd & $2.78 \%$ & $3.65 \%$ & $2.75 \%$ & $2.89 \%$ \\
5 th & $1.59 \%$ & $1.51 \%$ & $1.62 \%$ & $1.06 \%$ \\
7 th & $1.36 \%$ & $2.64 \%$ & $1.59 \%$ & $2.32 \%$ \\
9 th & $1.59 \%$ & $1.67 \%$ & $1.89 \%$ & $1.71 \%$ \\
11 th & $1.06 \%$ & $0.86 \%$ & $0.85 \%$ & $0.60 \%$ \\
13 th & $0.95 \%$ & $0.89 \%$ & $0.78 \%$ & $0.58 \%$ \\
THD & $4.85 \%$ & $5.51 \%$ & $4.74 \%$ & $5.28 \%$ \\
\hline \hline
\end{tabular}




\section{CONCLUSION}

Introduced in this paper is a method to increase the output impedance of a single-phase grid connected inverter with an $L C$ filter to improve the stability and harmonic reduction ability of the system when the inverter is connected to a weak distorted grid. By modeling the output impedance of the inverter, the relationship between output impedance and grid impedance can be investigated. The grid impedance can degrade the control performance of the inverter and make the system less stable. In order to mitigate this effect, PI controller parameters are adjusted to increase the output impedance, which can improve the ability for the harmonic reduction and the stability of the system. Finally, simulation and experiment results for a $1 \mathrm{~kW}$ single-phase grid connected inverter with an $L C$ filter verify the effectiveness of the proposed method.

\section{REFERENCES}

[1] Liserre, M., Teodorescu, R., Blaabjerg, F., "Stability of photovoltaic and wind turbine grid-connected inverters for a large set of grid impedance values," Power Electronics, IEEE Transactions on, vol.21, no.1, pp.263,272, Jan. 2006.

[2] Jian Sun, "Impedance-Based Stability Criterion for Grid-Connected Inverters," in Power Electronics, IEEE Transactions on , vol.26, no.11, pp.3075-3078, Nov. 2011.

[3] M. Céspedes and J. Sun, "Impedance shaping of three-phase gridparallel voltage-source converters," 2012 Twenty-Seventh Annual IEEE Applied Power Electronics Conference and Exposition (APEC), Orlando, FL, 2012, pp. 754-760.

[4] D. Yang, X. Ruan and H. Wu, "Impedance Shaping of the GridConnected Inverter with LCL Filter to Improve Its Adaptability to the Weak Grid Condition," in IEEE Transactions on Power Electronics, vol. 29, no. 11, pp. 5795-5805, Nov. 2014.

[5] Xiao-Qiang Li, Xiao-Jie Wu, Yi-Wen Geng, and Qi Zhang; "Stability Analysis of Grid-Connected Inverters with an LCL Filter Considering Grid Impedance", Journal of Power Electronics, Vol. 13, No. 5, September 2013.

[6] V. Blasko and V. Kaura, "A novel control to actively damp resonance in input LC filter of a three phase voltage source converter," Applied Power Electronics Conference and Exposition, 1996. APEC '96. Conference Proceedings 1996., Eleventh Annual, San Jose, CA, 1996, pp. 545-551 vol.2.

[7] F. Wang, J. L. Duarte, M. A. M. Hendrix and P. F. Ribeiro, "Modeling and Analysis of Grid Harmonic Distortion Impact of Aggregated DG Inverters," in IEEE Transactions on Power Electronics, vol. 26, no. 3, pp. 786-797, March 2011.

[8] Y. Tao, Q. Liu, Y. Deng, X. Liu and X. He, "Analysis and Mitigation of Inverter Output Impedance Impacts for Distributed Energy Resource Interface," in IEEE Transactions on Power Electronics, vol. 30, no. 7, pp. 3563-3576, July 2015.

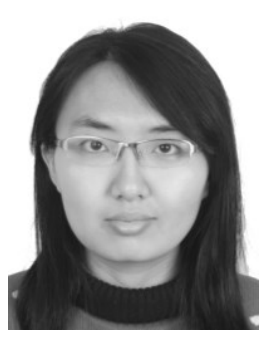

Jiao Jiao received her B.S. and M.S. degree in Electrical Engineering from China Agricultural University, Beijing, China, in 2011 and 2013, respectively. She is currently pursuing her Ph.D. degree in Electrical Engineering in the Electrical and Computer Engineering Department at Auburn University. Her current research interests include grid-connected inverter modeling, simulation and control.

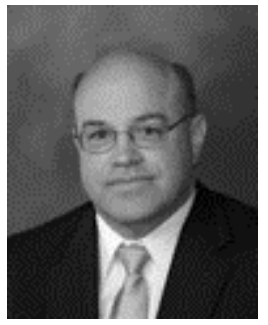

R. M. Nelms (F'04) received the B.E.E. and M.S. degrees in electrical engineering from Auburn University, Auburn, AL, USA, in 1980 and 1982, respectively, and the $\mathrm{Ph}$.D. degree in electrical engineering from Virginia Polytechnic Institute and State University, Blacksburg, VA, USA, in $1987 . \mathrm{He}$ is currently Professor and Chair of the Department of Electrical and Computer Engineering, Auburn University. His research interests are in power electronics, power systems, and electric machinery. Dr. Nelms is a registered Professional Engineer in Alabama. In 2004, he was named an IEEE Fellow "for technical leadership and contributions to applied power electronics." 